Artikel

\title{
SASTRA LISAN “AEK SIPITUDAI” DI DESA AEK SIPITUDAI \\ KECAMATAN SIANJUR MULA-MULA KABUPATEN \\ SAMOSIR (KAJIAN ANTROPOLOGI SASTRA)
}

Oleh

Queen Keren Happuck Samosir

NIM 2143210019

Dosen Pembimbing Skripsi

Dr. Arnita, S.Si., M.Si.

Telah Diverifikasi dan Dinyatakan Memenuhi

Syarat untuk Diunggah pada Jurnal Online

Editor,

Dr. M. Oky Fardian G., S.Sos., M.Hum. NIP 197901152005011002
Medan, Agustus 2018

Menyetujui :

Dosen Pembimbing Skripsi,

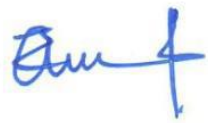

Dr. Arnita, S.Si., M.Si. NIP 197606212008122001 

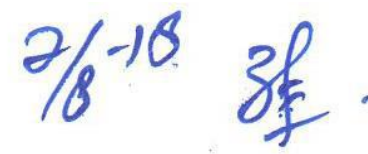

\title{
SASTRA LISAN “AEK SIPITUDAI" DI DESA AEK SIPITUDAI KECAMATAN SIANJUR MULA-MULA KABUPATEN SAMOSIR (KAJIAN ANTROPOLOGI SASTRA)
}

\author{
Queen Keren Happuck Samosir (queenkh04samosir@gmail.com) \\ Dr. Arnita, S.Si., M.Si. (arnita22@yahoo.com)
}

Penelitian ini bertujuan untuk mendeskripsikan unsur-unsur dan nilai-nilai budaya Batak yang terdapat di dalam cerita "Aek Sipitudai" yang berasal dari desa Aek Sipitudai. Teori yang digunakan dalam penelitian ini adalah teori Koentjaraningrat untuk membahas tentang unsur-unsur kebudayaan dan nilai-nilai budaya yang terdapat di dalam cerita. Metode yang digunakan dalam penelitian ini adalah metode deskriptif kualitatif dengan teknik pengumpulan data yang harus mendekati dan merekam cerita dari penutur cerita yang bertempat tinggal di desa tersebut. Teknik analisis data dengan mencatat temuan-temuan dan objekobjek yang akan dikaji, selanjutnya akan dilakukan pengelompokkan data dan mengklasifikasikan unsur-unsur dan nilai-nilai budaya yang terdapat dalam cerita. Hasil penelitian menunjukkan bahwa cerita "Aek Sipitudai" memiliki unsur budaya Batak diantaranya peralatan kehidupan manusia, mata pencaharian, sistem kemasyarakatan, bahasa, kesenian dengan berbagai jenisnya, sistem pengetahuan dan sistem religi serta memiliki nilai kekerabatan, nilai religi, nilai hasangapon, nilai uhum/konflik, dan nilai hagabeon yang sangat erat dengan tradisi dan adat istiadat masyarakat Batak.

\section{Kata Kunci: Sastra Lisan, Budaya, Aek Sipitudai}

\section{PENDAHULUAN}

Suku Batak Toba keberadaanya diakui, bahkan sangat dekat dengan kelompok masyarakat yang memilikinya. Sastra lisan adalah kesusasteraan yang mencakup ekspresi kesusasteraan warga, suatu keberadaan penyebarannya dari mulut ke mulut, sastra lisan tersebut akan mudah memudar. Sastra tulisan dalam penyampaiannya adalah melalui tulisan yang sudah dibukukan dan dibaca oleh orang banyak. Sastra tulisan ini banyak berasal dari sastra lisan misalnya satu dongeng yang diceritakan seseorang kemudian ditulis dan dibukukan oleh orang yang mendengarnya. 
Karya-karya sastra lisan tersebut telah banyak memberikan sumbangan yang berupa didaktis, filsafat, ilmu pengetahuan, dan lain-lain yang perlu diteliti dan diangkat kepermukaan melalui buku-buku yang meyangkut kepada karya sastra lisan tersebut agar masyarakat lain yang belum mengetahui menjadi tahu. Sebagai contoh sastra lisan Batak Toba ialah legenda. Legenda merupakan cerita yang mengisahkan terjadinya sesuatu yang dapat dibuktikan kebenarannya dan masih bisa dilihat bukti peninggalannya (Danandjaja, 1984:50). Nilai-nilai yang didapatkan dari sebuah legenda akan mengungkap kepercayaan masyarakat yang diajarkan secara turun temurun. Salah satu sastra lisan yang menggambarkan kebudayaan dan kepercayaan masyarakat Batak Toba adalah legenda Aek Sipitudai tepatnya berada di Pulau Samosir.

Nilai-nilai yang didapatkan dari sebuah legenda akan mengungkap kepercayaan masyarakat yang diajarkan secara turun temurun. Salah satu sastra lisan yang menggambarkan kebudayaan dan kepercayaan masyarakat Batak Toba adalah legendaAek Sipitudai tepatnya berada di Pulau Samosir. Pulau Samosir merupakan salah satu daerah asal orang Batak. "Aek Sipitudai" adalah salah satu objek wisata yang berada di Desa “Aek Sipitudai” Kecamatan Sianjur Mula-mula Kabupaten Samosir. Daya tarik utama objek wisata ini adalah kondisi tiap air memiliki pansuran yang memiliki rasa yang berbeda-beda. Menurut legenda yang diyakini masyarakat, sampai saat ini "Aek Sipitudai” memiliki sejarah yang berhubungan dengan si Raja Batak.

\section{METODE PENELITIAN}

Metode yang digunakan adalah metode kualitatif yang bersifat deskriptif berupa data-data dalam bentuk kata-kata atau gambar. Endraswara (2013:53) mengatakan, "Metode kualitatif adalah analisis data yang tidak mempergunakan perhitungan statistik, tetapi berupa kata-kata. Kualitas data ditentukan oleh pengambilan data secara mendalam. Metode penelitian ini memiliki maksud untuk melihat unsur-unsur dan nilai budaya yang terdapat pada sastra lisan "Aek Sipitudai” dengan kajian antropologi sastra menurut Koenjananingrat. 
HASIL DAN PEMBAHASAN PENELITIAN

1. Unsur-unsur Budaya Batak dalam Cerita "Aek Sipitudai"

Tabel 1. Unsur-unsur Budaya Batak dalam Cerita "Aek Sipitudai"

\begin{tabular}{|c|c|c|}
\hline No. & $\begin{array}{l}\text { Unsur-unsur } \\
\text { Budaya }\end{array}$ & Kata/Kalimat petunjuk \\
\hline \multirow[t]{3}{*}{1.} & \multirow[t]{3}{*}{$\begin{array}{l}\text { Peralatan } \\
\text { Kehidupan } \\
\text { Manusia }\end{array}$} & $\begin{array}{l}\text { a. Malang tidak bisa ditolak keduanya tak mampu } \\
\text { menahan diri, mereka pun bercinta layaknya } \\
\text { sepasang kekasih yang disaksikan alam Pussuk } \\
\text { Buhit di sebuah gubuk kecil ditengah hutan. }\end{array}$ \\
\hline & & $\begin{array}{l}\text { b. Jika sudah bertemu maka tegurlah dan pasangkan } \\
\text { cincin yang diberikan ibunya tersebut ke jari-jari } \\
\text { wanita itu. }\end{array}$ \\
\hline & & $\begin{array}{l}\text { c. Dengan waktu yang sudah di atur sampailah } \\
\text { ibunya Si Raja Lontung di permandian Air } \\
\text { Sipitudai. }\end{array}$ \\
\hline 2. & $\begin{array}{l}\text { Mata } \\
\text { Pencaharian }\end{array}$ & $\begin{array}{l}\text { Di hutan belantara itulah dari kecil hingga dewasa Siraja } \\
\text { Lontung dibesarkan dan dilatih untuk menaklukkan hutan } \\
\text { oleh ibunda si Boru Pareme dan Babiat Sitelpang yang } \\
\text { menjadi sahabatnya. }\end{array}$ \\
\hline \multirow[t]{4}{*}{3.} & \multirow[t]{4}{*}{$\begin{array}{l}\text { Sistem } \\
\text { Kemasyarakatan }\end{array}$} & $\begin{array}{l}\text { a. Sejak kecil keduanya sangat dekat dan terlihat } \\
\text { tidak layaknya saudara kandung (namariboto). }\end{array}$ \\
\hline & & $\begin{array}{l}\text { b. Si Raja Batak penguasa Sianjur Mula-mula } \\
\text { sangatlah marah karena perbuatan biadab mereka. }\end{array}$ \\
\hline & & $\begin{array}{l}\text { c. Dia ingin mencari paribannya puteri dari } \\
\text { pamannya (puteri dari saudara laki-laki), untuk } \\
\text { dijadikan istri atau parsonduk bolon. }\end{array}$ \\
\hline & & $\begin{array}{l}\text { d. Konon, hasil dari perkawinan mereka lahirlah } \\
\text { anak-anak dari Si Raja Lontung Si sia sada ina } \\
\text { yang memiliki arti yang sangat dalam yaitu } \\
\text { sembilan orang beribukan satu ibu (Si Boru } \\
\text { Pareme). }\end{array}$ \\
\hline \multirow[t]{3}{*}{4.} & \multirow[t]{3}{*}{ Bahasa } & $\begin{array}{l}\text { a. "Parhatia Habonanaran, Parninggala Sibola } \\
\text { tali, Hu ginjang so ra munggal, Hu toru sora } \\
\text { teleng" }\end{array}$ \\
\hline & & b. Na busuk manang boha pe ingkon maup. \\
\hline & & $\begin{array}{l}\text { c. Alai tahe mamusa Saribu Raja ndang mura, } \\
\text { ndang alani na samudar. }\end{array}$ \\
\hline
\end{tabular}




\begin{tabular}{|c|c|c|}
\hline 5. & $\begin{array}{l}\text { Kesenian } \\
\text { dengan berbagai } \\
\text { jenisnya }\end{array}$ & $\begin{array}{l}\text { Si boru Pareme pasrah dengan keadaan saat babiat } \\
\text { Sitelpang mendekat kepada dirinya. Dia pun } \\
\text { manggandung di tengah hutan belantara. }\end{array}$ \\
\hline \multirow[t]{3}{*}{6.} & \multirow[t]{3}{*}{$\begin{array}{l}\text { Sistem } \\
\text { Pengetahuan }\end{array}$} & $\begin{array}{l}\text { a. Saribu Raja sadar akan kesalahannya, akhirnya } \\
\text { jalan satu-satunya ia pergi merantau untuk } \\
\text { menghindari amarah dari saudara-saudaranya } \\
\text { yang berada di kampung halaman. }\end{array}$ \\
\hline & & $\begin{array}{l}\text { b. Di hutan belantara itulah dari kecil hingga dewasa } \\
\text { si Raja Lontung dibesarkan dan dilatih untuk } \\
\text { menaklukkan hutan oleh ibundanya Siboru } \\
\text { Pareme dan Babiat Sitelpang yang menjadi } \\
\text { sahabatnya. }\end{array}$ \\
\hline & & $\begin{array}{l}\text { c. Seiring berjalannya waktu Siraja Lontung } \\
\text { semakin dewasa dan ia ingin mencari pasangan } \\
\text { hidupnya. }\end{array}$ \\
\hline 7. & Sistem Religi & $\begin{array}{l}\text { Adik kandung dari Saribu Raja berencana ingin } \\
\text { membunuh kakaknya karena telah melanggar hukum } \\
\text { kuno yang sudah dijejakkan oleh "Debata Mula Jadi Na } \\
\text { Bolon" bahwa sedarah tidak diperbolehkan untuk } \\
\text { menikah. }\end{array}$ \\
\hline
\end{tabular}

Dari tabel 1 di atas menunjukkan bahwa cerita "Aek Sipitudai” mengandung tujuh unsur budaya diantaranya perlatan kehidupan manusia, mata pencaharian, sistem kemasyarakatan, sistem bahasa, kesenian dengan berbagai jenisnya, sistem pengetahuan, dan sistem religi. Ke tujuh unsur budaya ini akan dikaji berdasarkan kalimat atau paragraf yang dapat diuraikan sebagai berikut:

\section{a. Peralatan Kehidupan Manusia}

Salah satu aspek budaya menurut Koenjananingrat yaitu peralatan kehidupan manusia terdapat juga pada cerita "Aek Sipitudai" yang sudah mengenal cara atau tindakan manusia untuk membuat, memakai, dan memelihara seluruh peralatan hidupnya. Pada sastra lisan "Aek Sipitudai" ditemukan aspek budaya peralatan kehidupan manusia. Berikut adalah penggalan kalimat yang terdapat di dalam cerita "Aek Sipitudai".

"Malang tidak bisa ditolak keduanya tak mampu menahan diri, mereka pun bercinta layaknya sepasang kekasih yang disaksikan alam Pussuk Buhit di sebuah gubuk kecil ditengah hutan". 
Cerita "Aek Sipitudai" ini memiliki pengaruh yang besar terhadap perkembangan peralatan hidup dan teknologi. Sastra lisan "Aek Sipitudai” juga menunjukkan unsur budaya peralatan kehidupan manusia, berikut adalah penggalan kalimat yang menunjukkan adanya unsur budaya peralatan kehidupan manusia.

\section{"Jika sudah bertemu maka tegurlah dan pasangkan cincin yang}

diberikan ibunya tersebut ke jari-jari wanita itu”.

Kutipan di atas menunjukkan bahwa pada masa lampau masyarakat Batak sudah mengenal unsur budaya peralatan kehidupan manusia yakni masyarakat sudah mampu menciptakan pakaian dan perhiasan yang dibutuhkan dalam kehidupan sehari-hari. Dan, pada zaman sekarang masyarakat Batak harus menyematkan cincin di acara pernikahan saat melamar seorang puteri raja. Cerita "Aek Sipitudai" juga menggambarkan bahwa peralatan kehidupan manusia dipengaruhi oleh wadah atau tempat untuk membantu pekerjaan masyarakat, kutipan kalimatnya ditunjukkan pada kalimat:

"Dengan waktu yang sudah diatur sampailah ibunya si Raja

Lontung di permandian Aek Sipitudai”.

Pemandian "Aek Sipitudai” pada zaman dahulu kala dipergunakan raja-raja yang ada di desa tersebut sebagai tempat mandi, dengan wadah ini mereka mampu bertahan hidup dengan menciptakan sebuah tempat pemandian untuk memenuhi kebutuhan. Dan, sampai pada saat ini tempat mandi masih dikunjungi banyak orang yang datang ke tempat tersebut untuk berobat dan pada saat ini tempat pemandian ini sudah digunakan untuk tempat menyuci dan "Aek Sipitudai" digunakan sebgai sumber air minum untuk memenuhi kebutuhan sehari-hari seluruh penduduk disana.

\section{b. Mata Pencaharian}

Masyarakat Batak Toba dikenal dengan bangsa yang kuat dan gigih dalam mencari dan melengkapi kebutuhan sehari-harinya. Di dalam cerita sastra lisan "Aek Sipitudai" dijelaskan bahwa masyarakat pada saat itu mengenal namanya berburu ke hutan Belantara untuk melengkapi kebutuhan hidupnya.

Terdapat pada kutipan:

Di hutan belantara itulah dari kecil hingga dewasa Siraja Lontung dibesarkan dan dilatih untuk menaklukkan hutan oleh 
ibunda si Boru Pareme dan babiat sitelpang yang menjadi sahabatnya.

Kutipan ini menjelaskan bahwa kehidupan masyarakat Batak Toba tergantung kepada cara masyarakat untuk mencari makanan untuk memenuhi keberlangsungan hidupnya sehari-hari. Salah satunya berburu makanan ke hutan belantara untuk memenuhi kebutuhan pangan setiap hari. Dan, pada zaman sekarang masyarakat Batak harus rajin mencari pekerjaan untuk memenuhi kebutuhan primer atau sekunder setiap harinya.

\section{c. Sistem Kemasyarakatan}

Sastra lisan "Aek Sipitudai" mencerminkan sistem kemasyarakatan yang menjujung tinggi adt istiadat yang dikenal oleh suku Batak Toba. Cerita "Aek Sipitudai" menceritakan tentang sistem kekerabatan yang melekat pada diri Suku Batak Toba. Masyarakat Batak Toba mengenal istilah Dalihan Na Tolu dan sampai sekarang menjadi falsafat yang digunakan setiap upacara adat Suku Batak Toba. Terdapat pada kutipan berikut ini:

a. "Sejak kecil keduanya sangat dekat dan terlihat tidak layaknya saudara kandung (namariboto)".

b. "Si Raja Batak penguasa Sianjur Mula-mula sangatlah marah karena perbuatan biadab mereka".

c. "Dia ingin mencari paribannya puteri dari pamannya (puteri dari saudara laki-laki), untuk dijadikan istri atau parsonduk bolon.

Kalimat diatas menunjukkan bahwa sistem kemasyarakatan Batak Toba menjunjung tinggi kodrat dari seorang Raja adat, atau pihak hula-hula yang lebih menjungjung tinggi sistem kemasyarakatan Batak Toba. Sistem kekerabatan Batak Toba mengenal Dalihan Na Tolu. Masyarakat Batak harus tunduk dan selalu memegang teguh dan harus tunduk pada habatahon ho/ budaya batak. Fungsi dari Dalihan Na Tolu secara umum adalah menjaga integrasi masyarakat.

\section{d. Sistem Bahasa}

Bahasa adalah identitas suatu kelompok masyarakat. Bahasa bukan hanya berfungsi sebagai alat komunikasi namun dalam masyarakat Batak Toba bahasa adalah mempersatukan dengan yang lainnya. Sistem bahasa mencakup beberapa aspek budaya Batak Toba dapat berupa "umpasa dan umpama”. Dalam sastra 
lisan "Aek Sipitudai" terdapat umpasa dan umpama. Dapat dilihat dari kutipan di bawah ini:

a. "Parhatia Habonanaran, Parninggala Sibola tali, Hu ginjang so ra munggal, Hu toru sora teleng”.

b. "Na busuk manang boha pe ingkon maup".

c. "Alai tahe mamusa Saribu Raja ndang alani na samudar".

Penggunaan umpasa dalam kehidupan masyarakat Batak Toba sudah menjadi tradisi lisan yang digunakan di setiap acara adat batak Toba. Kalimat diatas memiliki arti kehidupan itu harus jujur dan adil, barang siapa yang melakukan kesalahan akan menerima ganjaran sesuai dengan apa yang diperbuat. Pada kutipan (a) terdapat sebuah umpama yang menggambarkan bahwa masyarakat Batak harus memiliki kepribadian dan perilaku yang adil bagi setiap teman di sekitarnya, umpama atau peribahasa di atas menunjukkan bahwa kehidupan masyarakat harus selalu menjunjung tinggi nilai kejujuran dan kebaikan dan harus dilaksanakan di dalam kehidupan sehari-hari.

Pada kutipan (b) kalimat pada kutipan ini menggambarkan bahwa bagi siapapun suku Batak yang melanggar janji harus hancur dan memiliki kehidupan kelam jika tidak berperilaku baik dan adil.Sedangkan, pada kutipan (c) kalimat ini memiliki arti bahwa dalam kehidupan masyarakat Batak yang melanggar janji akan dihukum, prinsip ini berlaku dari sejak dahulu kala sampai pada saat ini.

\section{e. Kesenian dengan berbagai Jenisnya}

Sastra lisan "Aek Sipitudai" menceritakan bahwa di dalam cerita masyarkat sudah mengenal dengan bahasa andung-andung, mangandungi. Mangandungi adalah serangkaian kalimat puitis yang disampaikan dengan menangis. Pada sastra lisan “Aek Sipitudai” terdapat unsur seni yang tinggi terdapat pada kutipan:

"Si boru Pareme pasrah dengan keadaan saat babiat Sitelpang mendekat kepada dirinya. Dia pun manggandung di tengah hutan belantara".

Kutipan di atas menunjukkan bahwa unsur budaya Batak di bidang kesenian sejak zaman dahulu kala sudah memiliki seni yang tinggi, dari alat musik seperti gendang (gondang), merupakan salah satu unsur budaya bidang kesenian. 


\section{f. Sistem Pengetahuan}

Masyarakat Batak Toba menggunakan pengetahuan mereka dengan memanfaatkan pikiran untuk bertindak dan melangkah ketempat lain demi mendapatkan kehidupan yang lebih baik.

Terdapat pada kutipan di bawah ini:

a. "Saribu Raja sadar akan kesalahannya, akhirnya jalan satu-satunya ia pergi merantau untuk menghindari amarah dari saudara-saudaranya yang berada di kampung halaman".

b. "Di hutan belantara itulah dari kecil hingga dewasa si Raja Lontung dibesarkan dan dilatih untuk menaklukkan belantara oleh ibundanya si Boru Pareme dan babiat sitelpang menjadi sahabatnya".

c. $\quad$ "Seiring berjalannya waktu si Raja Lontung semakin dewasa dan ingin mencari pasangannya."

Kutipan (a) menunjukkan bahwa pada zaman dahulu kala masyarakat Batak sudah pergi merantau untuk memudahkan dan membantu masyarakat untuk memudahkan hidup sehari-hari, kutipan itu juga menunjukkan bahwa masyarakat sudah mengetahui teknik atau cara untuk mengubah kehidupan menjadi lebih baik dengan pergi mencari nafkah ke tempat yang lebih baik dari pada di desanya sendiri, masyarakat pada zaman dahulu kala sudah mengenal istilah berpindah tempat/nomaden sehingga unsur budaya ini sampai sekarang sudah berlaku di kalangan masyarakat Batak.

Kutipan (b) menunjukkan bahwa masyarakat pada zaman dahulu kala mampu menaklukan hutan, dalam artinya mampu menguasai bidang-bidang atau tempat-tempat yang mereka gunakan untuk mencari nafkah, pada zaman dahulu kala hutan merupakan salah satu tempat penghasil makanan.

Kutipan (c) menggambarkan masyarakat Batak sudah mengenal sistem pengetahuan dengan mencari pasangan/jodoh agar kelak memiliki keturunan dan melanjutkan hubungan marga. Suku masyarakat Batak sudah mengenal pelaksanaan upacara pernikahan dan pelaksanaan adat istiadat dalam kehidupan sehari-hari masyarakat Batak serta tetap menjaga tradisi budaya masyarakat Batak Toba. 


\section{g. Sistem Religi}

Sistem kepercayaan atau sistem religi masyarakat Batak Toba pada sastra lisan "Aek Sipitudai" menggambarkan suku Batak Toba sebelum mengenal agama. Dari sastra lisan “Aek Sipitudai” ini menjelaskan bahwa masyarakat pada saat itu masih mempercayai hal-hal mistis, berdoa kepada pohon-pohon besar, memberikan persembahan, dan juga mempercayai benda-benda yang memiliki kekuatan gaib. Sistem religi ini terdapat pada kutipan:

"Adik kandung dari Saribu Raja berencana ingin membunuh kakaknya karena telah melanggar hukum kuno yang sudah dijejakkan oleh "Debata Mula Jadi Na Bolon" bahwa sedarah tidak diperbolehkan untuk menikah".

Pada zaman dahulu kala masyarakat Batak memiliki pemahaman bahwa alam dan segala isinya diciptakan oleh Ompung (Debata Mula Jadi Na Bolon). Dia berada di atas langit dan mempunyai nama-nama lain sesuai dengan tugas dan tempat kedudukannya. Sebagai Debata Mula Jadi Na Bolon, ia tinggal di langit dan merupakan maha pencipta.

\section{Nilai-nilai Budaya Batak dalam Sastra Lisan "Aek Sipitudai"}

Tabel 2. Nilai Budaya Batak dalam Cerita "Aek Sipitudai"

\begin{tabular}{|c|c|c|c|}
\hline No & $\begin{array}{c}\text { Nilai-Nilai } \\
\text { Budaya } \\
\text { Batak }\end{array}$ & Bahasa Batak Toba & Bahasa Indonesia \\
\hline \multirow[t]{3}{*}{1.} & \multirow[t]{3}{*}{$\begin{array}{l}\text { Nilai } \\
\text { Kekerabatan }\end{array}$} & $\begin{array}{l}\text { Adong do boru ni tatea } \\
\text { bulan sada sian boru na } \\
\text { margoar Boru Pareme, } \\
\text { Anak na margoar Saribu } \\
\text { Raja Linduat (kembar) } \\
\text { dohot siboru Pareme. }\end{array}$ & $\begin{array}{l}\text { Guru Tatea Bulan memiliki } \\
\text { puteri yang salah satunya } \\
\text { bernama Boru Pareme, Saribu } \\
\text { Raja dan Siboru Pareme } \\
\text { adalah anak kembarnya }\end{array}$ \\
\hline & & $\begin{array}{l}\text { Anggi ni Saribu Raja ma } \\
\text { ujung na marsakkap naeng } \\
\text { mamusa ahanai ala ndang } \\
\text { mangihutton adat dohot } \\
\text { uhum. }\end{array}$ & $\begin{array}{l}\text { Adik Kandung dari saribu } \\
\text { Raja berencana ingin } \\
\text { membunuh kakaknya karena } \\
\text { telah melanggar hukum. }\end{array}$ \\
\hline & & $\begin{array}{l}\text { Naeng } \\
\text { pariban na laho gabe } \\
\text { ripena/ parsonduk bolonna } \\
\text { “....didok Siboru Pareme } \\
\text { ma tu anakna : laho maho } \\
\text { anakku tu paridian na }\end{array}$ & \begin{tabular}{lr} 
Dia ingin & \multicolumn{2}{c}{ mencari } \\
paribannya puteri & dari \\
pamannya (puteri & dari \\
saudara laki-laki), untuk & dijadikan istri \\
parsinonduk bolon &
\end{tabular} \\
\hline
\end{tabular}




\begin{tabular}{|c|c|c|c|}
\hline & & $\begin{array}{l}\text { disan, inganan ni pariban } \\
\text { mu maridi. Lului ma } \\
\text { sarupa tu pardompahanku, } \\
\text { pangkulingi ma pasahat } \\
\text { ma tonakku jala } \\
\text { pamasukma tintin on tu } \\
\text { jari-jari na (jala laos } \\
\text { dilehon tintin) molo pas do } \\
\text { tintin on tu jarina, ima } \\
\text { paribanmi boru ni } \\
\text { tulangmu jala laos boan } \\
\text { ma ibana tuson,songoni } \\
\text { ma tona ni Boru Pareme." }\end{array}$ & $\begin{array}{l}\text { "....pesan Ibunya ialah } \\
\text { mencari perempuan yang } \\
\text { mirip dengan ibunya. Jika } \\
\text { mereka sudah bertemu maka } \\
\text { tegur lah dan pasangkan } \\
\text { cincin yang diberikan ibunya } \\
\text { tersebut ke jari-jari wanita itu. } \\
\text { Jika cin-cin tersebut cocok } \\
\text { maka ialah paribanmu boru } \\
\text { dari pamanmu. Lalu ajak dan } \\
\text { bawalah ia kesini. Begitulah } \\
\text { pesan dari ibunda Raja } \\
\text { Lontung kepadanya". }\end{array}$ \\
\hline 2. & Nilai Religi & $\begin{array}{l}\text { "Anggi ni Saribu Raja ma } \\
\text { ujung na marsangkap } \\
\text { naeng mamusa hahanai ala } \\
\text { ndang mangihuthon adat } \\
\text { dohot uhum naung } \\
\text { dipinahot ni Ompunta } \\
\text { Mula Jadi Nabolon, } \\
\text { angka na samudar ndang } \\
\text { boi marsiolian". }\end{array}$ & $\begin{array}{l}\text { Adik kandung dari Saribu } \\
\text { Raja berencana ingin } \\
\text { membunuh kakanya karena } \\
\text { telah melanggar hukum kuno } \\
\text { yang sudah dijejakkan oleh } \\
\text { Debata Raja Na Bolon yang } \\
\text { sedarah tidak boleh menikah. }\end{array}$ \\
\hline 3. & $\begin{array}{l}\text { Nilai } \\
\text { Hasangapon }\end{array}$ & $\begin{array}{l}\text { Anak na linduat na } \\
\text { margoar Saribu Raja } \\
\text { dohot Siboru Pareme }\end{array}$ & 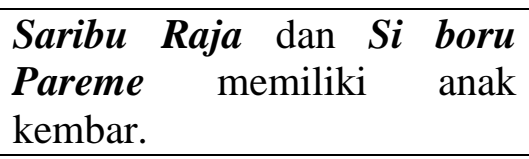 \\
\hline 4. & Nilai Uhum & $\begin{array}{l}\text { "Sip-sip naso binoto } \\
\text { marsihaholongan } \\
\text { nasida jala } \\
\text { mangulahon naso suman. } \\
\text { Ndang tartabunihon na } \\
\text { bau, naso sian pamotoan ni } \\
\text { Siraja Batak mangulahon } \\
\text { naso adat naso uhum ma } \\
\text { halaki nadua, na gabe } \\
\text { mambahen agong tu } \\
\text { bohini raja ni Sianjur } \\
\text { Mula-mula". }\end{array}$ & 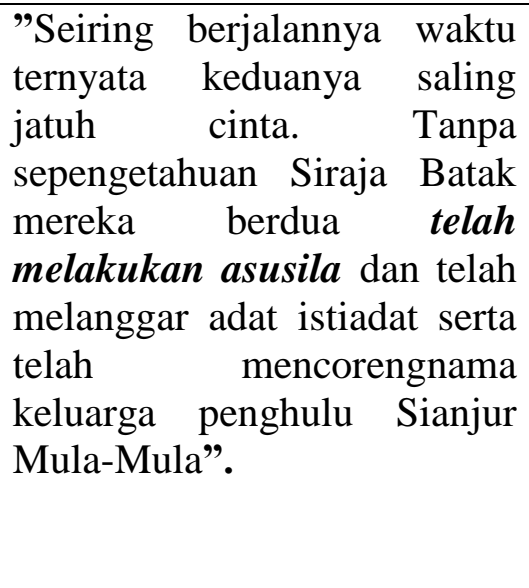 \\
\hline 5. & $\begin{array}{l}\text { Nilai } \\
\text { Hagabeon }\end{array}$ & 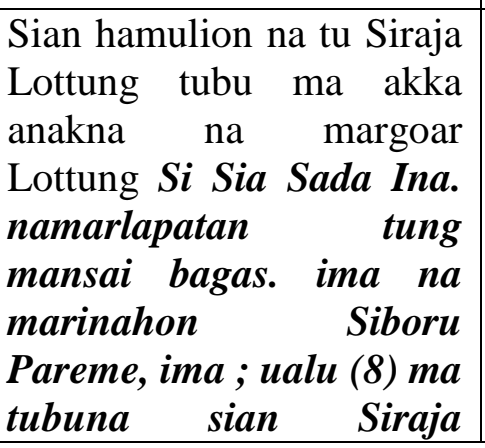 & $\begin{array}{l}\text { Hasil dari perkawinan mereka } \\
\text { lahirlah anak-anak dari siraja } \\
\text { lottung yang dikenal Lottung } \\
\text { Si Sia Sada Ina yang } \\
\text { memiliki arti yang sangat } \\
\text { dalam yaitu, sembilan (sia) } \\
\text { orang ber ibukan } \\
\text { (marinahon) si boru pareme } \\
\text { (sada ina). Yang terdiri dari }\end{array}$ \\
\hline
\end{tabular}




\begin{tabular}{|l|l|l|}
\hline & $\begin{array}{l}\text { Lottung. Pitu (7) ma baoa } \\
\text { jala sada (1) boru. }\end{array}$ & $\begin{array}{l}8 \text { (delapan) orang anaknya } \\
\text { dari suaminya si raja lottung } \\
7 \text { (tujuh) putra dan 1 (satu) } \\
\text { putri. }\end{array}$ \\
\hline
\end{tabular}

Dari tabel 2 diatas menunjukkan bahwa nilai-nilai budaya Batak Toba ini memberikan pengaruh besar untuk kemajuan suatu bangsa atau masyarakat. Karena nilai-nilai ini digunakan sebagai acuan untuk bertindak dalam kehidupan bermasyarakat. Nilai-nilai budaya yang terdapat di dalam cerita "Aek Sipitudai" adalah sebagai berikut:

\section{1) Nilai Kekerabatan}

Nilai kekerabatan yang terkandung dalam karya tersebut punya pengaruh bagi kehidupan masyarakat karena karya tersebut hidup. Sebagai alat pengesahan pranata-pranata dan lembaga-lembaga kebudayaan. Sistem kekerabatan masyarakat Batak Toba menempatkan 3 posisi penting yaitu hula-hula (somba maehula-hula), dongan tubu (manat mardongan tubu), dan boru (elek marboru) atau yang lebih dikenal dengan dalihan na tolu. Dalihan Na Tolu, yang khususnya hidup dikalangan tradisi etnik Batak mengajar masyarakat agar mempunyai kedudukannya di lembaga-lembaga adat. Berdasarkan yang tiga inilah masyarakat. Pada cerita "Aek Sipitudai" ditemukan nilai kekerabatan yang dibuktikkan dengan kalimat dibawah ini:

"Adong do boru ni Tatea Bulan sada sian boru na margoar Boru Pareme, Anak na margoar Saribu Raja Linduat (kembar) dohot siboru Pareme".

Terjemahan:

"Guru Tatea Bulan memiliki puteri yang salah satunya bernama Boru Pareme, Saribu Raja dan Siboru Pareme adalah anak kembarnya".

Pada kutipan di atas terdapat nilai kekerabatan yakni Dalihan Na Tolu, terdapat pada kata boru dan anak. Pada kalimat ini dijelaskan bahwa Tatea bulan memiliki sepasang anak kembar, yaitu satu perempuan dan satu anak laki-laki. Nilai kekerabatan juga ditunjukkan dengan kalimat yang ada dibawah ini:

Anggi ni Saribu Raja ma ujung na marsakkap naeng mamusa ahanai ala ndang mangihutton adat dohot uhum. 
Terjemahan:

"Adik Kandung dari saribu Raja berencana ingin membunuh kakaknya karena telah melanggar hukum”.

Nilai kekerabatan juga ditunjukkan dengan kutipan yang ada di atas bahwa sistem kekerabatan Batak Toba juga harus menghargai sanak saudaranya, adik-adik yang ada di dalam keluarganya, dan tidak diperkanankan untuk saling berteka. Pada kutipan kalimat di bawah ini terdapat nilai kekerabatan yang menunjukkan bahwa masyarakat Batak Toba juga harus melanjutkan generasi dengan mencari perempuan lain yng kelak akan menjadi pendamping hidupnya, disini dikenal kata "Pariban". Pariban adalah wanita yang pada zaman dahulu kala dijadikan sebagai pendamping hidup Batak Toba.

"Naeng buatonnama pariban na laho gabe ripenal parsonduk bolonna "....didok Siboru Pareme ma tu anakna : laho maho anakku tu paridian na disan, inganan ni pariban mu maridi. Lului ma sarupa tu pardompahanku, pangkulingi ma pasahat ma tonakku jala pamasukma tintin on tu jari-jari na (jala laos dilehon tintin) molo pas do tintin on tu jarina, ima paribanmi boru ni tulangmu jala laos boan ma ibana tuson, songoni ma tona ni Boru Pareme.”

Terjememahan:

"Dia ingin mencari paribannya puteri dari pamannya (puteri dari saudara laki-laki), untuk dijadikan istri atau parsinonduk bolon”. “....pesan Ibunya ialah mencari perempuan yang mirip dengan ibunya. Jika mereka sudah bertemu maka tegur lah dan pasangkan cincin yang diberikan ibunya tersebut ke jari-jari wanita itu. Jika cin-cin tersebut cocok maka ialah paribanmu boru dari pamanmu. Lalu ajak dan bawalah ia kesini. Begitulah pesan dari ibunda Raja Lontung kepadanya”.

Pada kutipan kalimat di atas ini menunjukkan pada zaman dahulu kala kehidupan masyarakat Batak Toba sangat mengikat erat yang namanya hubungan kekeluargaan. Nilai kekerabatan ini penting dalam kehidupan sosial masyarakat sebagaimana diatur dalam falsafat dalihan na tolu.

\section{2) Nilai Religi}

Nilai religi dalam sastra lisan “Aek Sipitudai” juga menceritakan sistem kepercayaan masyarakat Batak Toba pada zaman dahulu kala sebelum 
masyarakat mengenal agama. Dari cerita "Aek Sipitudai” masyarakat dapat dan masih banyak yang percaya dengan hal-hal magis seperti mempercayai datu (dukun), memberika persembahan kepada dukun, juga mempercayai benda-benda yang memiliki kekuatan. Hal ini terdapat pada kutipan sebagai berikut:

"Anggi ni Saribu Raja ma ujung na marsangkap naeng mamusa hahanai ala ndang mangihuthon adat dohot uhum naung dipinahot ni Ompunta Mula Jadi Nabolon, angka na samudar ndang boi marsiolian”.

Terjemahan:

"Adik kandung dari Saribu Raja berencana ingin membunuh kakanya karena telah melanggar hukum kuno yang sudah dijejakkan oleh Debata Raja Na Bolon yang sedarah tidak boleh menikah".

Cerita "Aek Sipitudai" menggambarkan bahwa masyarakat Batak Toba sejak zaman dahulu kala telah mengenal yang namanya agama atau sistem kepercayaan terbukti pada kutipan di atas. Kata "Debata Raja Na Bolon" adalah yang Maha Karya dan sumber segala kebaikan yang mengabulkan cita-cita dan pengharapan setiap orang yang takwa kepadanya. Masyarakat Batak Toba sangat menginginkan keinginan untuk hidup dengan umur panjang dengan menghormati dan menghargai sang pencipta, pada zaman dahulu kala sang pencipta memiliki kekerapan yang paling tinggi/ peringkat paling atas. Masyarakat Batak Toba juga menggunakan istilah "Amanta Debata, Debata do Na Martua, Debata Na Di Ginjang, Na Martua Debata, Ompunta Mula jadi Na Bolon, dan Ompunta Parasi Roha".

\section{3) Nilai Hasangapon}

Di dalam kehidupan masyarakat Batak toba orang harus memiliki nilai hasangapon. Hasangapon adalah orang yang memiliki kelebihan lebih dari dirinya, misalnya dia memiliki kekayaan, banyak harta, jabatan tinggi, dan memiliki banyak anak, anak laki-laki dan perempuan, dan merupakan keluarga yang terpandang sanggup sebagai orang yang sangap.

Nilai hasangapon ini terdapat pada kutipan dibawah ini:

"Anak na linduat na margoar Saribu Raja dohot Siboru

Pareme". 
Terjemahan:

"Mereka memiliki anak kembar yaitu Saribu Raja dan Siboru Pareme”.

\section{4) Nilai Uhum}

Nilai sosiologis yang terkandung dalam cerita Aek Sipitu Dai adalah kenyataan sosial dari cerita tersebut. Kenyataan sosial yang tampak disitu pertama adalah pelanggaran terhadap norma-norma adat kebudayaan Batak Toba pada zaman dulu yang sudah dilanggar oleh Saribu Raja dengan saudara kandungnya (ibotonya) Siboru Pareme. Dapat kita lihat kelakuan keduanya seperti kutipan di bawah ini :

"sip-sip naso binoto marsihaholongan ma nasida jala laos mangulahon naso suman. Ndang tartabunihon na bau, naso sian pamotoan ni Siraja Batak mangulahon naso adat naso uhum ma halaki nadua, na gabe mambahen agong tu bohini raja ni Sianjur Mula-mula”.

Terjemahan:

"seiring berjalannya waktu ternyata keduanya saling jatuh cinta. Tanpa sepengetahuan Siraja Batak mereka berdua telah melakukan asusila dan telah melanggar adat istiadat serta telah mencoreng nama keluarga penghulu Sianjur Mula-Mula".

Dalam kutipan di atas menunjukkan bahwa Saribu Raja dan Siboru Pareme telah melakukan hal yang seharusnya dilakukan oleh yang satu marga atau satu darah. Akan tetapi keduanya telah terlanjur jatuh cinta yang menimbulkan kemarahan bagi Siraja Batak yang pada saat itu sebagai Raja di Sianjur MulaMula.

\section{5) Nilai Hagabeon}

Nilai budaya Batak Toba hagabeon bermakna panjang umur, beranank cucu yang banyak. Masyarakat Batak Toba dikatakan gabe jika memiliki anak laki-laki dan perempuan, terutam laki-laki. . Pada sastra lisan "Aek Sipitudai" nilai hagabeon terdapat pada kutipan di bawah ini:

"Sian hamulion na tu Siraja Lottung tubu ma akka anakna na margoar Lottung Si Sia Sada Ina. namarlapatan tung mansai bagas. ima na marinahon Siboru Pareme, ima ; ualu (8) ma tubuna sian Siraja Lottung. Pitu (7) ma baoa jala sada (1) boru”. 
Terjemahan:

"hasil dari perkawinan mereka lahirlah anak-anak dari siraja lottung yang dikenal Lottung Si Sia Sada Ina yang memiliki arti yang sangat dalam yaitu, sembilan (sia) orang ber ibukan (marinahon) si boru pareme (sada ina). Yang terdiri dari 8 (delapan) orang anaknya dari suaminya si raja lottung 7 (tujuh) putra dan 1 (satu) putri”.

Cerita "Aek Sipitudai” melambangkan keturunan marga si Raja Lontung dan lahirlah marga-marga dari keturunan si Raja Lontung yaitu marga Sinaga, Situmorang, Pandiangan, Nainggolan, Simatupang, Siregar, Aritonang, Sihombing dan marga Simamora sebagai seorang puteri dan menjadi anak siappudan (anak terakhir) keturunan Raja Lontung dan si Boru Pareme.

\section{PENUTUP}

1) Hasil penelitian menunjukkan bahwa sastra lisan "Aek Sipitudai" memiliki unsur-unsur budaya antara lain (a) peralatan kehidupan manusia, (b) mata pencaharian, (c) sistem kemasyarakatan, (d) bahasa, (e) kesenian dengan berbagai jenisnya, (f) sistem pengetahuan dan (g) sistem religi.

2) Hasil penelitian menunjukkan bahwa sastra lisan ini memiliki nilai-nilai budaya yang masih diyakini oleh masyarakat diantaranya: nilai kekerabatan, nilai religi, nilai uhum/konflik, nilai hasangapon dan nilai hagabeon.

\section{DAFTAR PUSTAKA}

Dandandjaja, James. 1984. Foklor Indonesia Ilmu Gosip, Dongeng, dan lain-lain. Jakarta: PT. Temprint.

Endraswara. 2003. Metode Penelitian Sastra Epistemologi, Model, Teori dan Aplikasi. Universitas Negeri Yogyakarta: Pustaka Widyatama.

Harahap Basyral H dan Hotman M Siahaan.1987. “Orientasi Nilai-nilai Budaya Batak”. Jakarta: Sanggar William Iskandar.

Koentjaraningrat. 2007. Manusia dan Kebudayaan. Jakarta: Djambatan.

Moleong, J. Lexi. 2013. Metode Penelitian Kualitatif. Bandung: Remaja Rosdakarya.

Ratna, Nyoman Kutha. 2011. Antropologi Sastra: Peranan Unsur-unsur Kebudayaan dalam Proses Kreatif. Yogyakarta: Pustaka Belajar. 